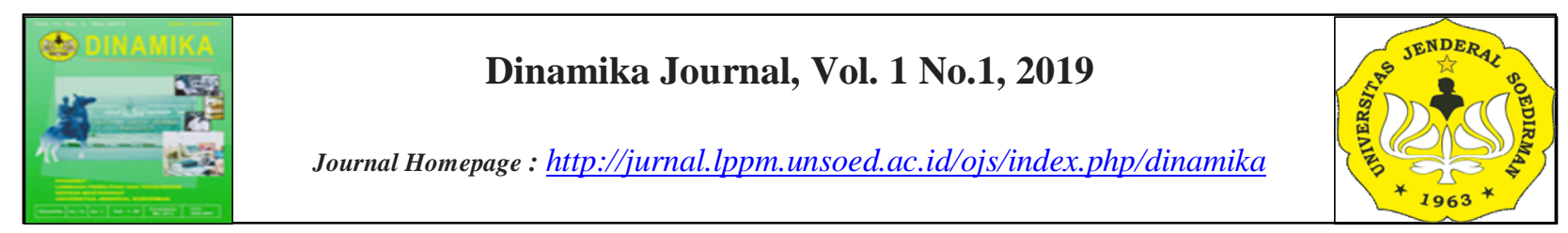

\title{
PEMBERDAYAAN KELOMPOK MUSTIKA LANGGENGJAYA MELALUI PENERAPAN CARA PRODUKSI PANGAN YANG BAIK
}

\author{
Rumpoko Wicaksono $^{1^{*}}$, Rifda Naufalin ${ }^{2}$ dan Dwi Nugroho Wibowo ${ }^{3}$ \\ ${ }^{1}$ Fakultas Pertanian, Universitas Jenderal Soedirman, Purwokerto \\ ${ }^{2}$ Fakultas Biologi, Universitas Jenderal Soedirman, Purwokerto \\ *Corresponding author : rumpoko.wicaksono@unsoed.ac.id
}

Received 5 May 2019; Accepted 23 June 2019; Available online 24 June 2019

\begin{abstract}
Abstrak
Pemberdayaan UMKM bidang pangan dimulai dengan menguatkan konstruksi keamanan pangan produk yang dihasilkan. Oleh karena itu, pemberdayaan UMKM di bidang pangan melalui sistem keamanan pangan menjadi upaya strategis untuk meningkatkan daya saing dan pendapatan masyarakat. Upaya yang dapat ditempuh untuk penguatan konstruksi keamanan pangan yaitu dengan menerapkan prinsip-prinsip higiene dan sanitasi produksi pangan serta praktik-praktik baik dalam pengelolaan penjaminan mutu dan keamanan pangan seperti yang tertuang dalam Cara Produksi Pangan yang Baik (CPPB) atau Good Manufacturing Practices (GMP). Metode yang digunakan yaitu metode survei terhadap kondisi CPPB UMKM mitra dan pendampingan implementasi prinsipprinsip CPPB. Mitra sasaran kegiatan yaitu UMKM Mustika Langgeng Jaya, Desa Binangun, Kecamatan Banyumas, Kabupaten Banyumas. Hasil evaluasi terhadap kondisi sarana produksi UMKM Mustika Langgeng Jaya menunjukkan jumlah ketidaksesuaian kritis sebanyak 7 temuan, ketidaksesuaian serius sebanyak 9 temuan, ketidaksesuaian mayor sebanyak 2 temuan, ketidaksesuaian minor sebanyak 1 temuan. Tindakan korektif yang dilakukan sebagai implementasi CPPB yaitu perbaikan sarana produksi pangan, sosialisasi dan pendampingan implementasi CPPB, pembuatan label kemasan pangan sesuai dengan syarat CPPB, dan pembuatan dokumen mutu.
\end{abstract}

Kata kunci: Pemberdayaan, UMKM, CPPB

\begin{abstract}
Empowering MSMEs in the food sector begins with strengthening the construction of food safety products produced. Therefore, the empowerment of MSMEs in the food sector through the food security system is a strategic effort to increase the competitiveness and income of the people. Efforts that can be taken to strengthen the construction of food security are by applying the principles of hygiene and sanitation of food production and good practices in the management of quality assurance and food safety as stated in Good Manufacturing Practices (GMP ). The method used is the survey method for the GMP conditions of MSME partners and mentoring the implementation of GMP principles. The partnernamely Mustika Langgeng Jaya, located in Binangun Village, Banyumas District, Banyumas Regency. The results of the evaluation of the condition of the MSME production facilities of Mustika Langgeng Jaya showed that there were 7 critical nonconformities, 9 serious nonconformities, 2 major nonconformities, 1 minor nonconformity. Corrective actions taken as the implementation of GMP are improvements to food production facilities,
\end{abstract}


socialization and assistance in the implementation of GMP, making food packaging labels in accordance with GMP requirements, and making quality documents.

Keywords: Empowerment, MSMEs, GMP

\section{PENDAHULUAN}

Usaha mikro, kecil dan menengah (UMKM) memberi andil yang besar sebagai sektor ekonomi yang strategis dalam menunjang ketahanan ekonomi di tingkat rumah tangga. Hal ini terkait dengan peran sertanya dalam meningkatkan pertumbuhan ekonomi, penciptaan lapangan pekerjaan, mudah beradaptasi dengan perubahan permintaan pasar, serta berkontribusi terhadap penyediaan produk dan kemudahan akses perolehan bahan pangan untuk konsumsi masyarakat.

Grumbul Wanasepi, Desa Binangun, Kabupaten Banyumas merupakan sentra pengelola emping melinjo dan makanan olahan lainya melalui komunitas Mustika Langgeng Jaya. UMKM tersebut mampu menjadi perusahaan industri rumah tangga yang memproduksi makanan olahan berbahan dasar hasil bumi lokal. Komunitas ini dibentuk sebagai tindak lanjut dari realisasi Kampoeng Mandiri "OGOP" (One "Grumbul" One Product) pada sekitar bulan Januari 2015 sebagai wadah untuk bermusyawarah antara pengrajin ataupun penghasil makanan olahan khususnya berbahan dasar melinjo dan pisang.

Di grumbul Wanasepi, ada sekitar 40 rumah yang bertindak sebagai pengrajin emping melinjo. Bahan baku melinjo diperoleh dari desa setempat. Hampir di setiap pekarangan rumah masyarakat menanam pohon melinjo. Di desa Binangun, pohon melinjo panen setahun sekali, berkisar antara bulan Mei sampai Juni. Dengan kisaran 6.780 batang pohon melinjo di desa Binangun yang tersebar di setiap RT, produksi panennya mencapai 4 sampai 5 ton setiap tahunnya.

Produk utama UMKM Mustika Langgeng Jaya adalah emping melinjo. UMKM ini juga telah mengembangkan produksi olahan melinjonya, menjadi kerupuk dan kue kering melinjo. Area pemasarannya baru meliputi Purwokerto, Banyumas dan sekitarnya. Terkait dengan harmonisasi ASEAN tahun 2015, UMKM pangan menghadapi tantangan dan peluang yang lebih besar, sehingga UMKM pangan perlu pemberdayaan yang lebih lebih intensif lagi. UMKM pangan tidak hanya dituntut untuk mampu menyediakan pangan yang aman dan bermutu bagi masyarakat, tetapi juga sekaligus siap menghadapi persaingan di pasar global, utamanya di negara-negara ASEAN.

Pemberdayaan UMKM bidang pangan dimulai dengan menguatkan konstruksi keamanan pangan produk yang dihasilkan. Oleh karena itu, pemberdayaan UMKM di bidang pangan melalui sistem keamanan pangan menjadi upaya strategis untuk meningkatkan daya saing dan pendapatan masyarakat (Rahayu et al., 2012). Upaya yang dapat ditempuh untuk penguatan konstruksi keamanan pangan yaitu dengan menerapkan prinsip-prinsip higiene dan sanitasi produksi pangan serta praktik-praktik baik dalam pengelolaan penjaminan mutu dan keamanan pangan seperti yang tertuang dalam Cara Produksi Pangan yang Baik (CPPB) atau Good Manufacturing Practices (GMP).

CPPB merupakan bagian dari penjaminan mutu yang menjamin bahwa produk yang dihasilkan konsisten mutunya dan dikendalikan dengan standar mutu yang sesuai dengan tujuan penggunaan dan kebutuhan pasar (Kumar dan Jha, 2015). Implementasi CPPB selain menjamin keamanan produk, juga meningkatkan kepercayaan konsumen, serta dapat 
meningkatkan nilai jual produk (Rodmanee dan Huang, 2013). Kegiatan pemberdayaan ini dilakukan dengan tujuan untuk: (1) mengetahui kondisi Mustika Langgeng Jaya berdasarkan evaluasi pelaksanaan CPPB, (2) mengintroduksi prinsip-prinsip CPPB kepada Mustika Langgeng Jaya, dan (3) mengimplementasikan tidakan korektif yang diperlukan sesuai dengan prinsip-prinsip CPPB.

\section{METODE}

Metode yang digunakan yaitu metode survei terhadap kondisi CPPB UMKM mitra dan pendampingan implementasi prinsip-prinsip CPPB. Mitra sasaran kegiatan yaitu Mustika Langgeng Jaya, Desa Binangun, Kecamatan Banyumas, Kabupaten Banyumas. Penilaian kondisi CPPB dilakukan dengan menggunakan formulir pemeriksaan sarana produksi industri rumah tangga menurut Peraturan Kepala BPOM RI Nomor HK.03.1.23.04.12.2207 tahun 2012 tentang Tata Cara Pemeriksaan Sarana Produksi Pangan Industri Rumah Tangga. Penggolongan level industri rumah tangga pangan dilakukan dengan kriteria seperti pada Tabel 1. Kriteria penyimpangan mengacu pada Peraturan Kepala BPOM RI Nomor HK.03.1.23.04.12.2206 tahun 2012 tentang Cara Produksi Pangan yang Baik untuk Industri Rumah Tangga (CPPB-IRT).

Tabel 1. Kategori level CPPB

\begin{tabular}{c|c|c|c|c}
\hline \multirow{2}{*}{ Level } & \multicolumn{4}{|c}{ Jumlah Penyimpangan (maksimal) } \\
\cline { 2 - 5 } & Minor & Mayor & Serius & Kritis \\
\hline I & 1 & 1 & 0 & 0 \\
II & 1 & $2-3$ & 0 & 0 \\
III & NA & $\geq 4$ & $1-4$ & 0 \\
IV & NA & NA & $\geq 5$ & $\geq 1$ \\
\hline
\end{tabular}

Keterangan:

- NA = tidak relevan.

- Minor = penyimpangan terhadap persyaratan "dapat" di dalam CPPB-IRT yang mempunyai potensi memengaruhi mutu (wholesomeness) produk pangan IRTP.

- Mayor = penyimpangan terhadap persyaratan "sebaiknya" di dalam CPPB-IRT yang mempunyai potensi memengaruhi efisiensi pengendalian keamanan produk pangan IRTP.

- Serius = penyimpangan terhadap persyaratan "seharusnya" di dalam CPPB-IRT yang mempunyai potensi memengaruhi keamanan produk pangan IRTP.

- Kritis = penyimpangan terhadap persyaratan "harus" di dalam CPPB-IRT yang akan memengaruhi keamanan produk pangan IRTP secara langsung dan/atau merupakan persyaratan yang wajib dipenuhi.

Pendampingan implementasi CPPB dilakukan dengan cara memfasilitasi pelaksanaan tindakan korektif dan pendampingan UMKM secara intensif selama 1 bulan kegiatan. Tindakan korektif yang dilakukan berupa kegiatan fisik dan nonfisik, disesuaikan dengan prioritas kepentingan dan kesanggupan pihak UMKM dalam implementasinya. 


\section{HASIL DAN PEMBAHASAN}

Hasil penilaian terhadap kondisi CPPB-IRT disajikan pada Tabel 2.

Tabel 2. Hasil penilaian kondisi CPPB-IRT Mustika Langgeng Jaya

\begin{tabular}{|c|c|c|}
\hline No & Elemen yang Diperiksa & $\begin{array}{c}\text { Kategori } \\
\text { Ketidaksesuaian } \\
\end{array}$ \\
\hline \multicolumn{3}{|c|}{ Lokasi dan Lingkungan Produksi } \\
\hline 1 & $\begin{array}{l}\text { Lokasi dan lingkungan industri rumah tangga pangan tidak } \\
\text { terawat, kotor dan berdebu. }\end{array}$ & Serius \\
\hline \multicolumn{3}{|c|}{ Bangunan dan Fasilitas } \\
\hline 2 & $\begin{array}{l}\text { Lantai, dinding, dan langit-langit tidak terawat, kotor, berdebu } \\
\text { dan/atau berlendir. }\end{array}$ & Serius \\
\hline 3 & Ventilasi, pintu, dan jendela tidak terawat, kotor, dan berdebu. & Serius \\
\hline \multicolumn{3}{|c|}{ Fasilitas dan Kegiatan Higiene dan Sanitasi } \\
\hline 4 & $\begin{array}{l}\text { Tidak tersedia sarana cuci tangan lengkap dengan sabun dan alat } \\
\text { pencuci tangan. }\end{array}$ & Serius \\
\hline 5 & Tidak tersedia tempat pembuangan sampah tertutup. & Kritis \\
\hline \multicolumn{3}{|c|}{ Kesehatan dan Higiene Karyawan } \\
\hline 6 & $\begin{array}{l}\text { Karyawan di bagian produksi pangan tidak mengenakan pakaian } \\
\text { kerja dan/atau mengenakan perhiasan. }\end{array}$ & Serius \\
\hline 7 & $\begin{array}{l}\text { Karyawan tidak mencuci tangan dengan bersih sewaktu memulai } \\
\text { mengolah pangan, sesudah menangani bahan mentah, atau } \\
\text { bahan/alat yang kotor, dan sesudah ke luar dari toilet/jamban. }\end{array}$ & Kritis \\
\hline 8 & $\begin{array}{l}\text { Karyawan bekerja dengan perilaku yang tidak baik (seperti } \\
\text { makan dan minum) yang dapat mengakibatkan pencemaran } \\
\text { produk pangan. }\end{array}$ & Mayor \\
\hline 9 & Tidak ada penanggung jawab higiene karyawan. & Mayor \\
\hline \multicolumn{3}{|c|}{ Pemeliharaan dan Program Higiene dan Sanitasi } \\
\hline 10 & Program higiene dan sanitasi tidak dilakukan secara berkala. & Serius \\
\hline 11 & $\begin{array}{l}\text { Sampah di lingkungan dan di ruang produksi tidak segera } \\
\text { dibuang. }\end{array}$ & Serius \\
\hline \multicolumn{3}{|c|}{ Penyimpanan } \\
\hline 12 & $\begin{array}{l}\text { Bahan pangan, bahan pengemas disimpan bersama-sama dengan } \\
\text { produk akhir dalam satu ruangan penyimpanan yang kotor, } \\
\text { lembap dan gelap dan diletakkan di lantai atau menempel ke } \\
\text { dinding. }\end{array}$ & Kritis \\
\hline 13 & Peralatan yang bersih disimpan di tempat yang kotor. & Kritis \\
\hline \multicolumn{3}{|c|}{ Pelabelan } \\
\hline 14 & $\begin{array}{l}\text { Label pangan tidak mencantumkan nama produk, daftar bahan } \\
\text { yang digunakan, berat bersih/isi bersih, nama dan alamat industri } \\
\text { rumah tangga pangan, masa kedaluwarsa, kode produksi, dan } \\
\text { nomor P-IRT. }\end{array}$ & Kritis \\
\hline \multicolumn{3}{|c|}{ Pengawasan oleh Penanggung Jawab } \\
\hline 15 & $\begin{array}{l}\text { Industri rumah tangga pangan tidak mempunyai penanggung } \\
\text { jawab yang memiliki Sertifikat Penyuluhan Keamanan Pangan } \\
\text { (PKP). }\end{array}$ & Kritis \\
\hline 16 & Industri rumah tangga pangan tidak melakukan pengawasan & Serius \\
\hline
\end{tabular}




\begin{tabular}{|c|l|c|}
\hline No & \multicolumn{1}{|c|}{ Elemen yang Diperiksa } & $\begin{array}{c}\text { Kategori } \\
\text { Ketidaksesuaian }\end{array}$ \\
\hline & internal secara rutin, termasuk monitoring dan tindakan koreksi. & \\
\hline \multicolumn{2}{|c|}{ Pencatatan dan Dokumentasi } & Serius \\
\hline 17 & Industri rumah tangga pangan tidak memiliki dokumen produksi. & Minor \\
\hline 18 & $\begin{array}{l}\text { Dokumen produksi tidak mutakhir, tidak akurat, tidak tertelusur } \\
\text { dan tidak disimpan selama 2 (dua) kali umur simpan produk } \\
\text { pangan yang diproduksi. }\end{array}$ & Kritis \\
\hline \multicolumn{2}{|c|}{ Pelatihan Karyawan } & 7 \\
\hline 19 & $\begin{array}{l}\text { Industri rumah tangga pangan tidak memiliki program pelatihan } \\
\text { keamanan pangan untuk karyawan. }\end{array}$ & 9 \\
\hline \multicolumn{2}{|c|}{ Jumlah ketidaksesuaian KRITIS } & 2 \\
\hline Jumlah ketidaksesuan SERIUS & 1 \\
\hline Jumlah ketidaksesuan MAYOR & IV \\
\hline Jumlah ketidaksesuan MINOR & \\
\hline
\end{tabular}

Ketidaksesuaian yang dijumpai pada aspek lokasi dan lingkungan produksi umumnya tergolong dalam ketidaksesuain serius. Kondisi lingkungan produksi dan fasilitas yang tidak terawat berpotensi menyebabkan kontaminasi terhadap produk. Debu merupakan sumber kontaminan yang berpeluang besar masuk ke ruang produksi. Debu dapat terbawa oleh angin, serangga dan hewan, serta oleh pekerja dan bahan yang masuk ke dalam ruang produksi. Adanya debu perlu mendapat perhatian yang serius karena pada debu dapat terbawa mikroorganisme baik mikroorganisme pembusuk maupun mikroorganisme patogen (Mortimore dan Wallace, 2001).

Berdasarkan SNI CAC/RCP 1:2011 (BSN, 2011), sumber kontaminasi potensial perlu dipertimbangkan ketika memutuskan pemilihan lokasi sarana produksi pangan, sertaefektivitas tindakan yangmungkindilakukan untuk melindungi pangan. Sarana produksi seharusnya tidak ditempatkan dilokasi yang secara jelas akan menimbulkan ancaman terhadap keamanan ataukelayakan pangan. Bangunan dan fasilitas UMKM juga masih perlu pembenahan agar dapat lebih menjamin tingkat keamanan pangan produknya.

Tindakan korektif yang dilakukan untuk menurunkan tingkat potensi bahaya di aspek ini, yaitu perbaikan lantai ruang produksi. Lantai diperbaiki dengan menggunakan keramik agar mudah dibersihkan dan disanitasi. Keramik merupakan bahan yang kuat dan direkomendasikan untuk industri pangan, selain lantai berbahan dasar resin (Carpentier, 2005). Hal ini sesuai dengan Peraturan Kepala Badan POM tahun 2012 tentang CPPB-IRT bahwa bangunan dan fasilitas industri rumah tangga pangan seharusnya menjamin bahwa pangan tidak tercemar oleh bahaya fisik, biologis dan kimia selama dalam proses produksi serta mudah dibersihkan dan disanitasi. Selain itu, lantai dengan dinding seharusnya tidak membentuk sudut mati atau sudut siku-siku yang dapat menahan air, hal ini sesuai dengan Peraturan Menteri Perindustrian Republik Indonesia Nomor 75/M-IND/PER/7/2010 tentang Pedoman Cara Produksi Pangan Olahan yang Baik.

Perbaikan sarana produksi tidak ada artinya tanpa kesadaran dari pihak UMKM untuk menerapkan praktik-praktik terkait dengan cara produksi. Sehubungan dengan hal tersebut, maka kegiatan sosialisasi dan pendampingan implementasi CPPB juga dilakukan. Sosialisasi CPPB bemanfaat sebagai pemahaman awal bagi pihak UMKM tentang sistem higiene dan sanitasi dalam pembuatan produk olahan pangan pada aspek pekerja, tempat 
pengolahan dan lingkungan, serta peralatan produksi. Implementasi CPPB juga akan memudahkan pihak UMKM untuk memperoleh pengakuan mutu dan keamanan pangan oleh lembaga terkait, karena CPPB merupakan prasyarat untuk perolehan PIRT maupun sertifikat SNI produk, GMP, HACCP, dan sebagainya.

Hasil penilaian kondisi pada aspek higiene dan kesehatan karyawan menunjukkan bahwa kondisi higiene dan kesehatan perlu mendapat perhatian serius untuk diperbaiki. Hal ini mengingat bahwa ada kemungkinan terjadi kontaminasi silang, yaitu kontaminasi dari satu bahan pangan olahan ke bahan pangan olahan lainnya melalui kontak langsung atau melalui pekerja pengolahan, kontak permukaan atau melalui air dan udara. Kesehatan dan higiene karyawan yang baik dapat menjamin bahwa karyawan yang kontak langsung maupun tidak langsung dengan pangan tidak menjadi sumber pencemaran. Tindakan korektif yang dilakukan untuk menekan kemungkinan timbulnya bahaya kontaminasi produk yaitu dengan pembiasaan penggunaan pakaian kerja atau celemek yang bersih saat mengolah makanan, serta selalu memperhatikan kebersihan tangan pengolah makanan.

Ketidaksesuaian dalam pelabelan tergolong dalam kategori kritis. Kemasan pangan harus diberi label yang jelas dan informatif untuk memudahkan konsumen dalam memilih, menangani, menyimpan, mengolah dan mengonsumsi pangan. Ketidaksesuaian dalam menangani dan ketidakjelasan informasi masa kedaluwarsa pangan dapat berbahaya bagi konsumen. Tindakan korektif yang dilakukan adalah pembuatan label pangan yang memenuhi ketentuan yang tercantum dalam Peraturan Pemerintah Nomor 69 Tahun 1999 tentang Label dan Iklan Pangan. Berdasrkan peraturan tersebut, label produk pangan sekurang-kurangnya memuat nama produk, daftar bahan yang digunakan, berat bersih atau isi bersih, nama dan alamat produsen, serta tanggal, bulan, dan tahun kedaluwarsa.

Pencatatan dan dokumentasi merupakan persyaratan penting untuk pelaksanaan program pengendalian proses yang baik (Vasconcellos, 2005).Pencatatan dan dokumentasi yang baik diperlukan untuk memudahkan penelusuran masalah yang berkaitan dengan proses produksi dan distribusi, mencegah produk melampaui batas kedaluwarsa, memudahkan auditor dalam mengevaluasi kegiatan operasional secara keseluruhan serta mutu produk akhir, sehinggakeefektifan sistem pengawasan pangan menjadi lebih baik (Patel dan Chotai, 2011). Menurut Peraturan Menteri Perindustrian Republik Indonesia Nomor 75/M-IND/PER/7/2010 tentang Pedoman Cara Produksi Pangan Olahan yang Baik, pencatatan dan dokumentasi disimpan sampai produk melampaui masa kedaluwarsanya. Lebih lanjut ditentukan dalam Peraturan Kepala Badan POM tahun 2012 tentang CPPBIRT, bahwa penyimpanan catatan dan dokumen dapat disimpan selama 2 (dua) kali umur simpan produk pangan yang dihasilkan.

Tindakan korektif yang dilakukan yaitu melakukan pendampingan dalam penyusunan dokumen mutu. Dokumen penjaminan mutu yang disusun di UMKM mitra terdiri atas pedoman mutu, prosedur mutu, instruksi kerja, dan formulir mutu. Pembuatan dokumen penjaminan mutu dilaksanakan dengan melakukan pengisian formulir mutu yang bertujuan untuk mengetahui dan mengontrol proses pembuatan produk agar mudah untuk diawasi dalam berlangsungnya proses produksi. 


\section{KESIMPULAN DAN SARAN}

\section{Kesimpulan}

Kondisi CPPB Mustika Langgeng Jaya masuk ke dalam level IV. Tindakan pemberdayaan yang telah dilakukan untuk peningkatan ke level yang lebih baik, yaitu menerapkan tindakan korektif sesuai dengan persyaratan CPBB, meliputi perbaikan sarana produksi pangan, sosialisasi dan pendampingan implementasi CPPB, pembuatan label kemasan pangan sesuai dengan syarat $\mathrm{CPPB}$, dan pembuatan dokumen mutu.

\section{Saran}

Perlu pembentukan dan penguatan tim penjaminan mutu di tingkat UMKM untuk menjamin penerapan CPPB dapat dilaksanakan secara berkelanjutan.

\section{UCAPAN TERIMAKASIH}

Ucapan terimakasih kepada pihak Kemenristek Dikti melalui hibah KKN PPM yang telah memfasilitasi kegiatan ini dan kepada pihak Mustika Langgeng Jaya, Binangun yang telah bersedia untuk menjadi mitra kegiatan, serta kepada mahasiswa peserta KKN PPM Binangun yang turut membantu dalam melaksanakan program pemberdayaan dan pendampingan UMKM mitra dalam implementasi CPPB.

\section{DAFTAR PUSTAKA}

Badan Standardisasi Nasional. 2011. Rekomendasi Nasional Kode Praktis - Prinsip Umum Higiene Pangan (CAC/RCP 1-1969, Rev. 4-2003, IDT).

Carpentier, B. 2005. Improving the design of floors. In: H.L.M. Lelieveld, M.A. Mostert, and J. Holah (Eds.). Handbook of Hygiene Control in Food Industry. CRC Press, Boca Raton.

Kumar, N., A. Jha. 2015. Latest trend in drugs regulatory guidance on 'Good Manufacturing Practices'. International Journal of Pharmaceutical Sciences and Bussines Management 3(10): 10-16.

Mortimore, S., C. Wallace. 2001. Food Industry Briefing Series: HACCP. Blackwell Science, Great Britain.

Patel, K.T., N.P. Chotai. 2011. Documentation and records: Harmonized GMP requirements. Journal of Young Pharmacists 3(2): 138-150.

Peraturan Kepala Badan Pengawas Obat dan Makanan Republik Indonesia Nomor HK.03.1.23.04.12.2206 tahun 2012 tentang Cara Produksi Pangan yang Baik untuk Industri Rumah Tangga. 
Peraturan Kepala Badan Pengawas Obat dan Makanan Republik Indonesia Nomor HK.03.1.23.04.12.2207 tahun 2012 tentang Tata Cara Pemeriksaan Sarana Produksi Pangan Industri Rumah Tangga.

Peraturan Menteri Perindustrian Republik Indonesia Nomor 75/M-IND/PER/7/2010 tentang Pedoman Cara Produksi Pangan Olahan yang Baik (Good Manufacturing Practices).

Peraturan Pemerintah Republik Indonesia Nomor 69 tahun 1999 tentang Label dan Iklan Pangan.

Rahayu, W.P., H. Nababan, P. Hariyadi., Novinar. 2012. Keamanan Pangan dalam Rangka Peningkatan Daya Saing Usaha Mikro, Kecil, dan Menengah untuk Penguatan Ekonomi Nasional. Makalah Widyakarya Nasional Pangan dan Gizi X, Jakarta, 2021 November 2012.

Rodmanee, S., W.C. Huang. 2013. Hygiene and manufacturing practices, interagency collaboration, and a proposal for improvement: A case study of community food enterprise in Thailand. International Journal of Social Science and Humanity 3(3): 222-226.

Vasconcellos, J.A. 2005. Quality Assurance for the Food Industri, a Practical Approach. CRC Press, New York. 